\title{
An Imported Case of Disseminated Cysticercosis and Taeniasis
}

\author{
Fukumi Nakamura-Uchiyama, Ken-ichiro Kobayashi and Kenji Ohnishi
}

Key words: disseminated cysticercosis, neurocysticercosis, taeniasis solium, autoinfection

(Intern Med 51: 347-348, 2012)

(DOI: 10.2169/internalmedicine.51.6549)
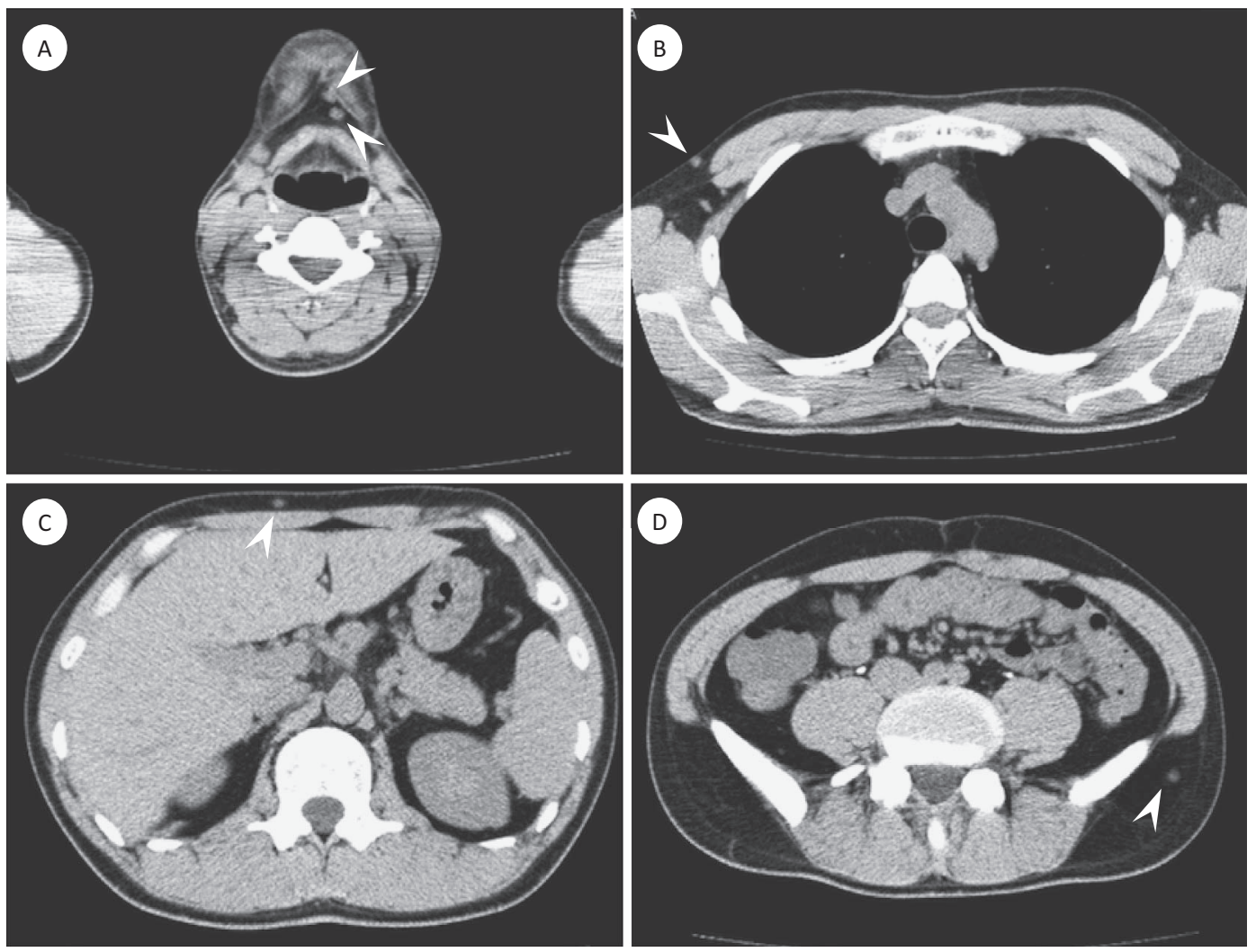

Picture 1.

A 31-year-old Japanese man had visited India three times on business between August 2008 and April 2009. The initial lesion appeared in December 2009 as a single subcutaneous painless nodule on the neck, and the lesions gradually increased in number. In April 2010 he expelled worm fragments. He was referred to us in May 2010. Characteristic skin biopsy findings (protoscolex and invaginated neck) and serological studies strongly indicated cysticercosis. The expelled worm was identified as Taenia solium by molecular analysis because it did not show the typical characteristic morphology of plogrottids. Whole body CT revealed twenty subcutaneous lesions (Picture 1) and a brain MRI showed thirty cystic lesions exhibiting a typical 'hole-with-a-dot' sign that is highly characteristic of neurocysticercosis (1) (Picture 2A and B) though no neurological symptoms were observed. We diagnosed disseminated cysticercosis, which is a very rare manifestation of neurocysticercosis (2) and taeniasis solium. He was successfully treated with albendazole. 

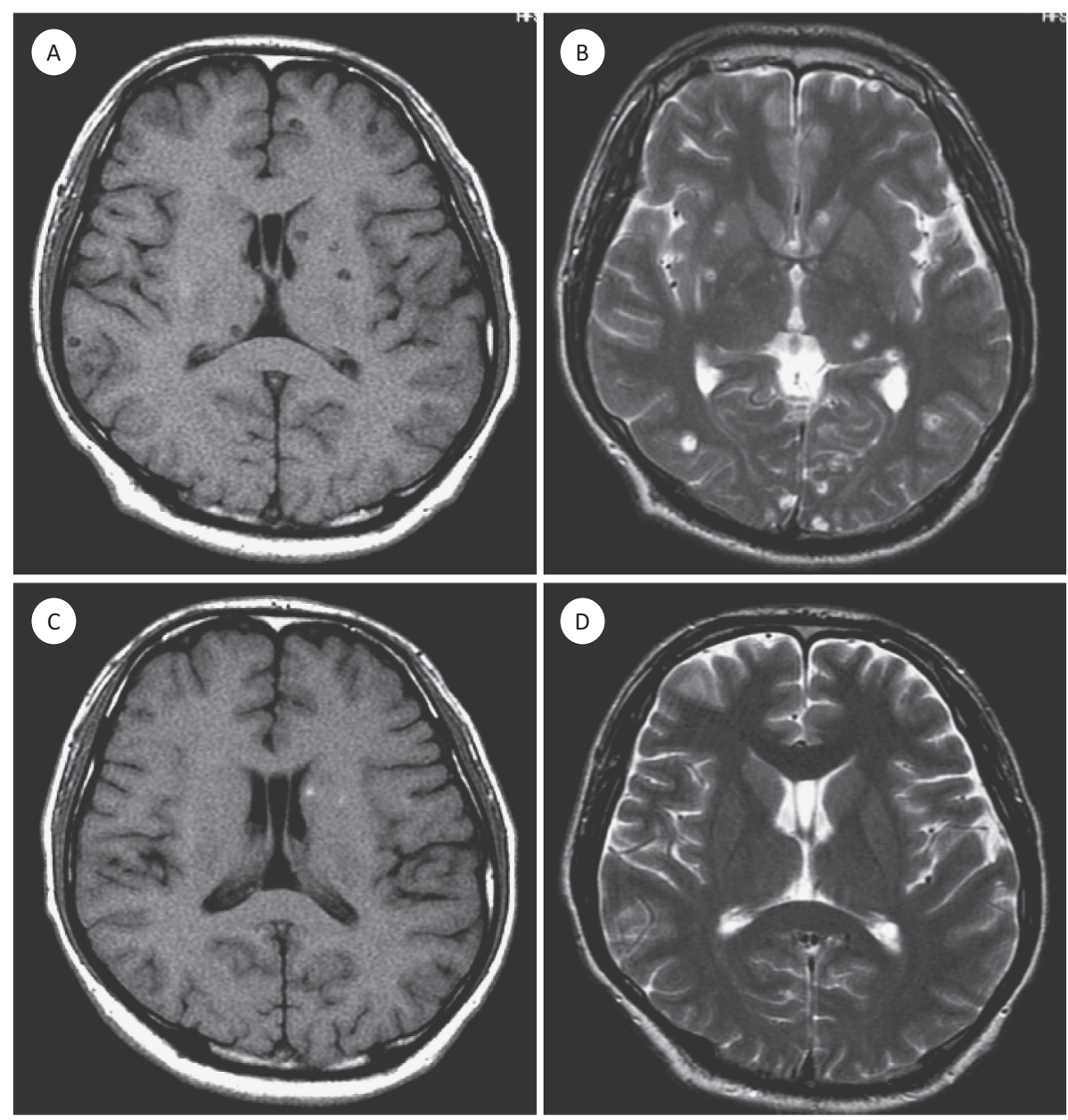

Picture 2.

The subcutaneous and intracranial lesions had completely disappeared after 4 weeks (Picture 2C and D).

The authors state that they have no Conflict of Interest (COI).

\section{References}

1. Del Brutto OH, Rajshekhar V, White AC Jr, et al. Proposed diagnostic criteria for neurocysticercosis. Neurology 57: 177-183, 2001.

2. Bhalla A, Sood A, Sachdev A, Varma V. Disseminated cysticercosis: a case report and review of the literature. J Med Case Reports 2: 137-139, 2008.

(C) 2012 The Japanese Society of Internal Medicine http://www.naika.or.jp/imindex.html 